\title{
New Allopathic Medical Schools Train Fewer Family Physicians Than Older Ones
}

\author{
Brian Beachler, MD, Yalda Jabbarpour, MD, Douglas B. Kamerow, MD, MPH, \\ Elizabeth Wilkinson, BA, Zachary Levin, BA, and Andrew Bazemore, MD, MPH
}

The first significant expansion of allopathic medical schools since the 1970s was anticipated to produce more physicians capable of addressing the nation's current and projected primary care shortages. However, our analysis of the early outputs of new allopathic medical schools suggests that these students were nearly $40 \%$ less likely to specialize in family medicine than existing schools. ( $\mathrm{J}$ Am Board Fam Med 2019;32:653-654.)

\section{Keywords: Family Physicians, Medical Schools, Primary Health Care, Students}

The likelihood of future shortages of adult primary care physicians is of great concern for policy makers as the US population grows and ages. ${ }^{1}$ Responding to projections of physician shortages in particular specialties and geographies, the Liaison Committee on Medical Education accredited 26 new allopathic medical schools between 2002 and 2018., ${ }^{2,3}$ Other investigators have not evaluated whether graduates from these institutions are entering fields with the greatest shortages, such as family medicine.

We used the 2018 American Medical Association Masterfile to compare self-reported specialty choice of resident physicians who graduated from the 14 US allopathic medical schools that were accredited after 2002 to those at the remaining 118 US allopathic schools, for the years 2015 to 2017. The remaining newly accredited medical schools did not have a graduating class at the time of the analysis and are not included. We limited our analysis

This article was externally peer reviewed.

Submitted 21 March 2019; revised 18 June 2019; accepted 18 June 2019.

From the Christiana Care Health System, Wilmington, DE (BB); Robert Graham Center, Washington, DC (YJ, DBK, EW); University of Minnesota School of Public Health, Minneapolis, MN; American Board of Family Medicine, Lexington, $\mathrm{KY}(\mathrm{AB})$.

Funding: none.

Conflict of interest: $\mathrm{AB}$ is an employee of the American Board of Family Medicine.

Corresponding author: Brian Beachler, Christiana Care Family Medicine. 1401 Foulk Rd Suite 100B, Wilmington, DE 19803. (E-mail: brian.j.beachler@christianacare.org). to resident physicians 3 years from medical school graduation; therefore, subspecialties are not represented in this analysis. The number of physicians from new allopathic medical school graduating early enough to have entered subspecialties by the time of the survey was too small for comparison. We found that graduates of the new medical schools were nearly $40 \%$ less likely than their colleagues at established medical schools to enroll in family medicine residency programs (Table 1). They were more likely to seek residency training in adult specialties such as general surgery (30\%) and OB/Gyn (42\%).

Expanding primary care access has clear relationship to better health outcomes and lower costs. ${ }^{4}$ A limited primary care workforce puts those benefits at risk. Increasing specialization among internists and pediatricians, paired with the growth of our aging population, leaves primary care physician growth particularly dependent on family medicine. While a small number now, students from new allopathic medical schools are projected to account for $39 \%$ of the total growth in allopathic enrollees by 2022, putting these schools in a unique position to fill the need in the primary care workforce. $^{3}$ As more medical schools graduate their first class of students, further studies will need to investigate whether the trend presented here is persistent and if workforce needs are being appropriately addressed by medical school expansion.

To see this article online, please go to: http://jabfm.org/content/ 32/5/653.full. 
Table 1. 10 Most Common Specialties Among Graduates (2015 to 2017) at New and Established Allopathic Medical Schools

\begin{tabular}{lcccc}
\hline Specialty & $\begin{array}{c}\text { Graduates from } \\
\text { New Schools (\%) }\end{array}$ & $\begin{array}{c}\text { Graduates from } \\
\text { Established Schools (\%) }\end{array}$ & $\begin{array}{c}\text { Net Difference } \\
(\%)\end{array}$ & $\begin{array}{c}\text { Relative } \\
\text { Difference }\end{array}$ \\
\hline Anesthesiology & 4.46 & 5.42 & -0.96 & $-21.52 \%{ }^{*}$ \\
Diagnostic Radiology & 2.96 & 2.66 & 0.30 & $11.28 \%$ \\
Emergency Medicine & 10.16 & 8.06 & 2.10 & $26.05^{\dagger}$ \\
Family Medicine & 6.14 & 8.56 & -2.42 & $-39.41 \%^{\dagger}$ \\
General Surgery & 9.54 & 7.32 & -1.41 & $30.33 \%^{\dagger}$ \\
Internal Medicine & 19.39 & 20.8 & 2.22 & $-7.27 \%$ \\
Obstetrics \& Gynecology & 7.42 & 5.2 & 0.26 & $42.69 \%^{\dagger}$ \\
Orthopedic Surgery & 3.80 & 3.54 & 2.51 & $7.34 \%$ \\
Pediatrics & 12.46 & 9.95 & 0.27 & $25.23 \%{ }^{\dagger}$ \\
Psychiatry & 4.73 & 4.46 & 50,704 & $6.05 \%$ \\
Total Students & 2,264 & & & \\
\hline
\end{tabular}

Note: $8.59 \%$ and $7.38 \%$ of residents from new and established medical schools did not respond with their specialty choice.

*Equates $P<.05$ by $\chi^{2}$ analysis.

${ }^{\dagger}$ Equates $P<.01$ by $\chi^{2}$ analysis.

The new medical schools included are Central Michigan University College of Medicine, Cooper Medical School of Rowan University, Florida Atlantic University Charles E. Schmidt College of Medicine, Florida International University Herbert Wertheim College of Medicine, Frank H. Netter MD School of Medicine at Quinnipiac University, Geisinger Commonwealth School of Medicine, Donald and Barbara Zucker School of Medicine at Hofstra Northwell, Oakland University William Beaumont School of Medicine, Paul L. Foster School of Medicine at Texas Tech University Health Sciences Center, University of Arizona College of Medicine-Phoenix, University of California, Riverside School of Medicine, University of Central Florida College of Medicine, University of South Carolina School of Medicine Greenville, and Virginia Tech Carilion School of Medicine and Research Institute.

\section{References}

1. Petterson SM, Liaw WR, Phillips RL Jr, Rabin DL, Meyers DS, Bazemore AW. Projecting US primary care physician workforce needs: 2010-2025. Ann Fam Med 2012;10:503-9.

2. Adler B, Biggs WS, Bazemore AW. State patterns in medical school expansion, 2000-2010: variation, discord, and policy priorities. Acad Med 2013;88:1849.
3. Association of American Medical Colleges. Results of the 2017 Medical School Enrollment Survey. May 2018. Available from: https://store.aamc.org/resultsof-the-2017-medical-school-enrollment-survey. html. Accessed June 12, 2019.

4. Starfield B, Shi L, Macinko J. Contribution of primary care to health systems and health. Milbank Q 2005;83:457-502. 